\title{
Patient Satisfaction: A Valid Indicator for the Quality of Primary Care?
}

\section{Tonio Schoenfelder*}

Department of Public Health, Dresden Medical School, Germany

Many countries have been implementing Pay for Performance (P4P) programs with the intention to improve the quality of care [1]. Primary care physicians and practices are rewarded with incentives based on the performance of predefined quality indicators such as management of hypertension or diabetes care. The California P4P Program is the largest of the United States, representing 10 million insured persons and 35,000 participating physicians [2,3]. The United Kingdom implemented the largest P4P program world-wide, the Quality and Outcomes Framework (QOF). Financial incentives can amount to up to $25 \%$ of a general practitioners' income [2]. One essential performance measure of both $\mathrm{P} 4 \mathrm{P}$ programs are patient experiences. The level of satisfaction with the received care determines the financial bonus that is given to the physician or medical practice. The weighting of this component varies from $15 \%$ in the British QOF to $30 \%$ in the California P4P model $[3,4]$. If a physician's income depends on patient experiences, consequently the question arises whether there is a link between satisfaction and health-care quality. In other words, did satisfied patients receive better care than unsatisfied ones?

Studies have evidenced that satisfaction with the perceived health service quality is an important determinant whether a patient complies with prescribed treatment plans, seeks medical advice, and maintains a continuing relationship with his or her medical practitioner, which can affect the subsequent resulting health outcome [5-7]. For example, improvements in outcomes in relation to satisfaction levels such as blood pressure and blood sugar, less complications in surgical patients, and lower mortality were found by several studies [8-11]. Dissatisfaction appears to lead to malpractice litigations [12] and doctor shopping, which can cause high costs and inefficiencies in health care systems [13].

If the association between patient experiences and health outcomes is related to better health-care quality, this requires that patients are able to assess the technical skill and medical competence of their physician. However, many study results indicate that patients may have a certain lack of medical knowledge and are not able to adequately assess the appropriateness of their treatment. For example, Kang et al. [14] examined the ability of patients to understand given information regarding an upcoming glaucoma surgery. Although most patients were generally satisfied with the received information, only a minority was able to demonstrate a good overall understanding of their surgical problem. Since many patients are not able to judge the technical quality they might look for proxy indicators they believe those are related to the quality of care. Many studies support this assumption. Accordingly, satisfaction ratings are mostly influenced by variables reflecting the personal qualities of physicians such as friendliness, courtesy, and respect and by amenities like cleanliness and quality of food $[15,16]$.

Approaches to increase satisfaction ratings may also have negative effects on patients or may lead to unnecessary costs in a health care system. Research shows that patient satisfaction strongly correlates with the extent to which expectations are fulfilled [17]. This might create strong incentives for primary care physicians within the framework of P4P systems to order requested tests or treatments that are desired by the patient though medically unnecessary or even riskful. In addition, physicians might lay the focus on satisfying the patient and therefore refrain from providing them with full information about tests and treatments, including negative sides, as well as avoiding uncomfortable issues such as consequences of obesity, smoking, and non-adherence. Recent studies seem to support this argument. Nearly half of US primary care physicians believe that their own patients were receiving too much medical care and they identified systemic financing incentives as a reason for that [18]. Another study showed that the most satisfied patients in a sample of 52,000 adult patients had greater total health-care and prescription drug expenditures, more inpatient admissions, and increased mortality risk [19].

If patient experiences are used as performance indicators in reimbursement systems it is important to understand what makes patients satisfied and to what extent providers can influence satisfaction ratings. The literature suggests that patient satisfaction is a multidimensional concept which is not yet fully defined. Part of that concept are aspects which are not under the control of the health professional such as patients' socio-demographic characteristics (e.g. education and age) and their health status [17]. Accordingly, satisfaction scores may reflect the demographic mix and clinical picture of the patients a medical practice serves rather than the quality of care provided. This calls into question if it is fair to reward providers for satisfied patients and penalize them for dissatisfied ones.

Research leaves open if patient experiences with received care can serve as a valid quality indicator which should be utilized for reimbursement purposes. Even though the association with some health outcomes is unquestionable there are also drawbacks which can have negative effects on the quality of primary care. Despite the problems of using patient satisfaction as a quality indicator, its measurement provides unique information regarding the process of care as seen through the patients' eyes that cannot be replaced by other performance indicators. Their feedback may highlight areas for quality improvement that physicians may have not considered before. Patients still provide the best source of accurate information on issues such as clarity of explanations or barriers to obtaining care [20].

\section{References}

1. Scheffler RM (2010) Pay For Performance (P4P) Programs in Health Services: What is the Evidence? World Health Report (2010) Background Paper No, 31.

2. Cromwell J, Trisolini MG, Pope GC, Mitchell JB, Greenwald LM (2011) Pay for Performance in Health Care: Methods and Approaches. RTI Press publication, USA.

3. California Pay for Performance Program (2012) Integrated Health Association.

4. Elovainio R (2010) Performance incentives for health in high-income countries key issues and lessons learned. World Health Report (2010) Background Paper, 32.

*Corresponding author: Tonio Schoenfelder, Department of Public Health Dresden Medical School Fetscherstraße 7401307, Dresden, Germany; Tel: 49151 2270 2233; E-mail: tonio.schoenfelder@gmx.de

Received August 21, 2012; Accepted August 24, 2012; Published August 27 2012

Citation: Schoenfelder T (2012) Patient Satisfaction: A Valid Indicator for the Quality of Primary Care? Primary Health Care 2:e106. doi:10.4172/21671079.1000e106

Copyright: @ 2012 Schoenfelder T. This is an open-access article distributed under the terms of the Creative Commons Attribution License, which permits unrestricted use, distribution, and reproduction in any medium, provided the original author and source are credited. 
Citation: Schoenfelder T (2012) Patient Satisfaction: A Valid Indicator for the Quality of Primary Care? Primary Health Care 2:e106. doi:10.4172/21671079.1000e106

5. O'Brien MK, Petrie K, Raeburn J (1992) Adherence to medication regimens: updating a complex medical issue. Med Care Res Rev 49: 435-454.

6. Car-Hill RA (1992) The measurement of patient satisfaction. J Public Health Med 14: 236-249.

7. Parchman ML, Burge SK (2004) The Patient-Physician Relationship, Primary Care Attributes, and Preventive Services. Fam Med 36: 22-27.

8. Kaplan SH, Greenfield S, Ware JE Jr (1989) Assessing the Effects of PhysicianPatient Interactions on the Outcomes of Chronic Diseases. Med Care 27: S110-S127.

9. Kane RL, Maciejewsky M, Finch M (1997) The Relationship of Patient Satisfaction with Care and Clinical Outcomes. Med Care 35: 714-730.

10. Devine EC (1992) Effects of Psychoeducational Care for Adult Surgical Patients: A Meta-Analysis of 191 Studies. Patient Educ Couns 19: 129-142.

11. Glickman SW, Boulding W, Manary M, Staelin R, Roe MT, et al. (2010) Patient Satisfaction and Its Relationship With Clinical Quality and Inpatient Mortality in Acute Myocardial Infarction. Circ Cardiovasc Qual Outcomes 3: 188-195.

12. Stelfox HT, Gandhi TK, Orav EJ, Gustafson ML (2005) The relation of patient satisfaction with complaints against physicians and malpractice lawsuits. Am J Med 118: 1126-1133.

13. Guo Y, Kuroki T, Yamashiro S, Koizumi S (2002) Illnes behavior and patient satisfaction as correlates of self-referral in Japan. Fam Pract 19: 326-332.
14. Kang KD, Abdul Majid AS, Kwag JH, Kim YD, Yim HB (2010) A prospective audit on the validity of written informed consent prior to glaucoma surgery: an Asian perspective. Graefes Arch Clin Exp Ophthalmol 248: 687-701.

15. Otani K, Kurz RS, Harris LE (2005) Managing primary care using patient satisfaction measures. J Healthc Manag 50: 311-324.

16. Schoenfelder T, Klewer J, Kugler J (2011) Determinants of patient satisfaction a study among 39 hospitals in an in-patient setting in Germany. Int J Qual Health Care 23: 503-509.

17. Crow R, Gage H, Hampson S, Hart J, Kimber A, et al. (2002) The measurement of satisfaction with healthcare: implications for practice from a systematic review of the literature. Health Technol Assess 6:1-244.

18. Sirovich BE, Woloshin S, Schwartz LM (2011) Too Little? Too Much? Primary Care Physicians' Views on US Health Care. A Brief Report. Arch Intern Med 171: 1582-1585.

19. Fenton JJ, Jerant AF, Bertakis KD, Franks P (2012) The Cost of Satisfaction. A National Study of Patient Satisfaction, Health Care Utilization, Expenditures, and Mortality. Arch Intern Med 172: 405-411.

20. Epstein KR, Laine C, Farber NJ, Nelson EC, Davidoff F (1996) Patients' Perceptions of Office Medical Practice: Judging Quality through the Patients Eyes. Am J Med Qual 11: 73-80. 